\title{
Investigating Theoretical PV Energy Generation Patterns with Their Relation to the Power Load Curve in Poland
}

\author{
Jakub Jurasz and Jerzy Mikulik \\ Department of Engineering Management, Faculty of Management, AGH University, 30-039 Kraków, Poland \\ Correspondence should be addressed to Jakub Jurasz; jakubkamiljurasz@gmail.com
}

Received 18 January 2016; Accepted 31 March 2016

Academic Editor: Wilfried G. J. H. M. Van Sark

Copyright (C) 2016 J. Jurasz and J. Mikulik. This is an open access article distributed under the Creative Commons Attribution License, which permits unrestricted use, distribution, and reproduction in any medium, provided the original work is properly cited.

\begin{abstract}
Polish energy sector is (almost from its origin) dominated by fossil fuel feed power. This situation results from an abundance of relatively cheap coal (hard and lignite). Brown coal due to its nature is the cheapest energy source in Poland. However, hard coal which fuels $60 \%$ of polish power plants is picking up on prices and is susceptible to the coal imported from neighboring countries. Forced by the European Union (EU) regulations, Poland is struggling at achieving its goal of reaching $15 \%$ of energy consumption from renewable energy sources (RES) by 2020. Over the year 2015, RES covered $11.3 \%$ of gross energy consumption but this generation was dominated by solid biomass (over $80 \%$ ). The aim of this paper was to answer the following research questions: What is the relation of irradiation values to the power load on a yearly and daily basis? and how should photovoltaics (PV) be integrated in the polish power system? Conducted analysis allowed us to state that there exists a negative correlation between power demand and irradiation values on a yearly basis, but this is likely to change in the future. Secondly, on average, daily values of irradiation tend to follow power load curve over the first hours of the day.
\end{abstract}

\section{Introduction}

International trends clearly indicate an increasing role of renewable energy sources in covering current and future demand on electric energy. Since the year 2004, Poland has been a member of the European Union. One of the main obligations of the EU members is to reduce their impact on the natural environment by increasing RES share in the energy mix. Polish energy system is based on domestic fossil fuels, particularly hard and brown coal, which enable Poland to generate over $83 \%$ of its electric energy [1]. Specificity of hard and brown coal fueled power plants predisposed them to be large baseload power plants which have a limited ability to swiftly ramp output or reduce power generation [2].

According to the URE (Energy Regulatory Authority) [3] data, by the end of the year 2015, Poland had $200 \mathrm{MW}$ installed capacity in biogas power plants, $51 \mathrm{MW}$ in photovoltaic systems, $982 \mathrm{MW}$ in hydropower plants, $1033 \mathrm{MW}$ in biomass power plants, $4.253 \mathrm{GW}$ in wind parks, and 44 power units realizing technology of cogeneration whose installed capacity cannot be determined. Nondispatchable generation (wind and solar) is not evenly distributed in Poland. The majority of wind parks are located near Baltic Sea whereas almost $40 \%$ of photovoltaic power plants are located in the eastern frontiers of Poland.

Development of RES in Poland is a response to the EU regulation and the increasing social awareness of the global climate change.

Variable energy sources are a serious challenge for the power grid operator and people responsible for energy system development [4]. So far, the impact of RES on polish power grid was limited but the example of Germany (which has very similar wind and solar conditions) shows that RES can strongly contribute to covering energy demand. By the end of the year 2015, the installed capacity of photovoltaics (39.55 GWp) and wind turbines (38.57 GW) in Germany [5] exceeded that available in all polish power plants $(39.3 \mathrm{GW})$ [6]. Inspired by the Germany case-study, we discuss in this paper the variable nature of solar energy in Poland, juxtaposing it with varying patterns of energy demand. Similar but quite not the same research was the scope of several selected publications. Book edited by Kleissl [7] is 
a compendium of state-of-the-art knowledge on solar energy forecasting and assessment. It gives most recent information on reliable data sources and investigated the concept of spatial complementarity between photovoltaic stations. Rowlands et al. [8] investigated the concept of spatial distribution impact on the smoothness of energy yield from PV systems. Dispersion of PV power units may lead to a decrease in energy generation but has a larger correlation coefficient (CC) with national energy demand. De Jong et al. [9] went even further and analyzed the correlation between selected RES and juxtaposed them with electricity load curve. Authors point to the act that wind and solar energy may strongly contribute to water saving during dry season, which is some sort of trade-off in Brazil, between energy generation and watering crop fields. In [10], authors have analyzed correlation between theoretical energy generation from PV systems dispersed among several dozen locations in Poland. They found that equal spatial distribution of installed capacity leads to an increased energy yield and reduces the variability of power output by half.

\section{Materials}

2.1. Irradiation. Solar Radiation Data (SoDa) [11] is a web service offering access to a number of international databases on radiation, altitude, astronomy, atmosphere, meteorological data, and typical years. In this research, time series were obtained from Monitoring Atmospheric Composition and Climate Radiation (MACC-RAD) subproject service which provides values of global, direct, and diffuse irradiation with a time step ranging from $1 \mathrm{~min}$ to 1 month. Data is available from 2004-02-01 up to two days ago. In case of Poland (above $45^{\circ}$ of latitude), the spatial resolution is approximately 4-5 kilometers. Irradiation time series covering the period 2010-2014 were collected for 39 cities, which have more than 100,000 inhabitants. Those cities collectively represent slightly over $45 \%$ of polish urban population and almost $30 \%$ of total number of inhabitants. The spatial distribution of mentioned cities is depicted in Figure 1 against a backdrop of irradiation and PV theoretical energy yield across European countries.

2.2. Power Load. Data concerning aggregated electrical energy demand in Poland was obtained from Polish Power Lines (PSE pol. Polskie Sieci Elektroeneretyczne) [13] which is responsible for energy transmission whilst maintaining required standards of National Electrification System (KSE pol. Krajowy System Elektroenergetyczny) safety. Inter alia PSE provides data on power load, energy generation from wind parks, and structure of international energy exchange. Data on power load is available in a 15-minute time step and covers period from 2002 up to one day ago. In this study, data concerning power load was obtained for the years 2010-2014. This data was further used when investigating its correlation with irradiation and impact of PV on energy demand; in some cases, power demand was calculated into energy demand. Figure 2 depicts the monthly variability of power load over the last fourteen years. A slightly increasing trend in power demand is visible and it is simultaneously accompanied by dwindling ratio of minimal to maximal power demand. In recent years peak load tended to shift from winter months to summer ones; this is mainly due to increasing number of air conditioners [14] and less severe weather conditions in winter.

\section{Methods}

3.1. Correlation between Sites. First of all, a correlation coefficient between all pairs of time series was calculated in order to determine whether or not energy generation from PV installations in Poland will follow the same patter. In total, 741 values were obtained. Secondly mentioned correlation coefficients were assigned to the corresponding distance between pairs of sites. It is important to note that, prior to calculating correlation coefficients, selected irradiation values equal to zero were removed from time series. Basically, the site with earliest occurrence of sunlight and that with latest sunset determined the time span for all time series for a given day.

3.2. Relation of Irradiation to Power Load. The relation of irradiation to power load values was investigated on annual and daily time scales. In case of yearly variability, mean monthly values of irradiation and power load were calculated for each month separately. After that, they underwent a normalization procedure to 0-1 range. In order to assess mentioned relation on a daily time scale, irradiation time series from each site were summarized, thus yielding an aggregated time series which covered the period from 2010 to 2014 with a 15 -minute time step. In this part of analysis, only those hours of the day when irradiation may occur were investigated. Average monthly timeframe for each day was estimated based on sunrise and sunset hours. Finally, based on the 2010-2014 time series, a typical pattern of a power load and irradiation, for given timeframe over day, was calculated.

3.3. PV Integration to the Energy System. An analysis of the $\mathrm{PV}$ systems integration into the polish energy system concentrated on their potential to cover current and minimize maximal energy demand and their impact on energy demand variability. In order to answer those research questions, the following assumptions have been made. Photovoltaic systems nominal power will be equally distributed among 39 previously selected locations. Energy yield from PV power units will be calculated in a 15-minute time step for the years 2010-2014 based on methods described in papers [15, 16]. As an energy surplus from PV installation, we will understand a situation when over given period PV generates more electrical energy than is demanded; this is taken into consideration when generation from PV was greater than current demand; otherwise, energy surplus equals 0 . In case of energy surpluses from PV presented in Figure 8, they are presented as a ratio to the total energy production from PV. What is more, a ratio of maximal to mean energy demand has been calculated based on net energy demand which is understood as gross energy demand decreased by energy generated from photovoltaics. Variability index of energy demand time series was calculated as a ratio of its standard deviation to mean. 


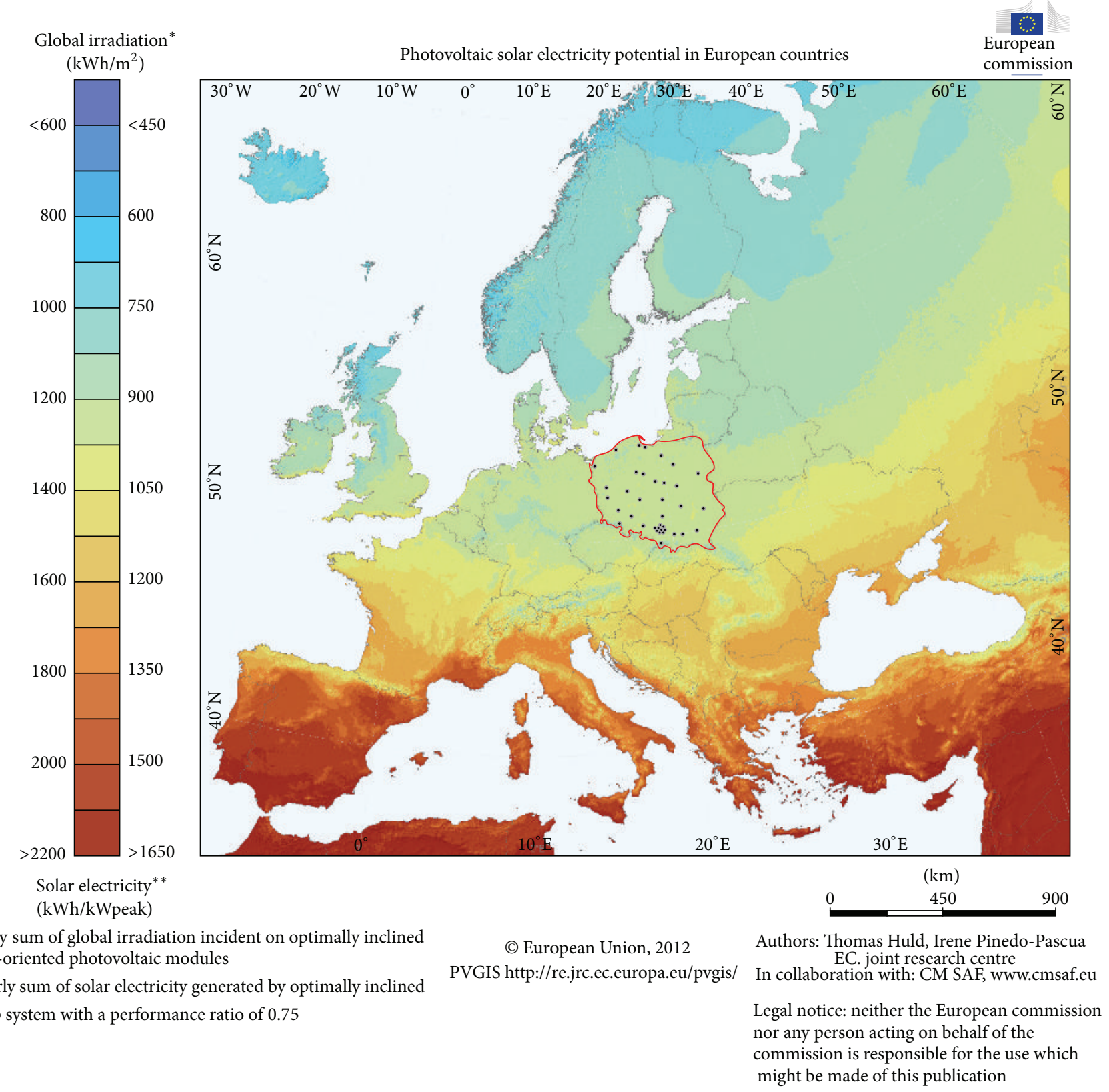

FIGURE 1: Global irradiation incident on optimally inclined PV modules in Europe. Key: Polish border outline: red line; dots: selected cities. Map source: [12].

\section{Results and Discussion}

In this part, we present results of conducted calculations, in the same order as they were described in previous section.

\subsection{Correlation between Sites: Spatial Distribution Smoothing} Effect. We begin by analyzing the values of correlation coefficients between irradiation time series. Figures 3 and 4 present how those values change with increasing distance between sites.

In case of a 15-minute time step (Figure 3), the CCs are aligned along straight line with only several outliers; this is indicated by high value of determination coefficient $\left(R^{2}\right)$ equal to 0.95 . It is important to note that with an increasing distance between sites a correlation coefficient is decreasing, reaching minimal value equal to 0.71 , whereas for observations with 1-minute time step points are much more dispersed $\left(R^{2}=0.5\right)$, and additionally the minimal value of CC is equal to 0.31 . According to [17], the smaller the correlation coefficient, the better it is for the operation of energy system and transmission networks. What is more, calculations show that variability of energy generation from dispersed systems is lesser than from a one central PV farm. But one condition must be met, the total area on which dispersed PV 


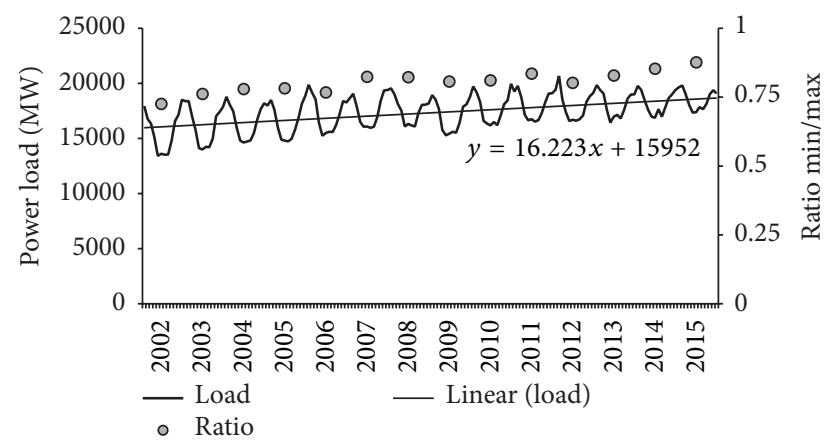

FIGURE 2: Mean monthly power load and the ratio of its minimal to maximal values of for a given year.

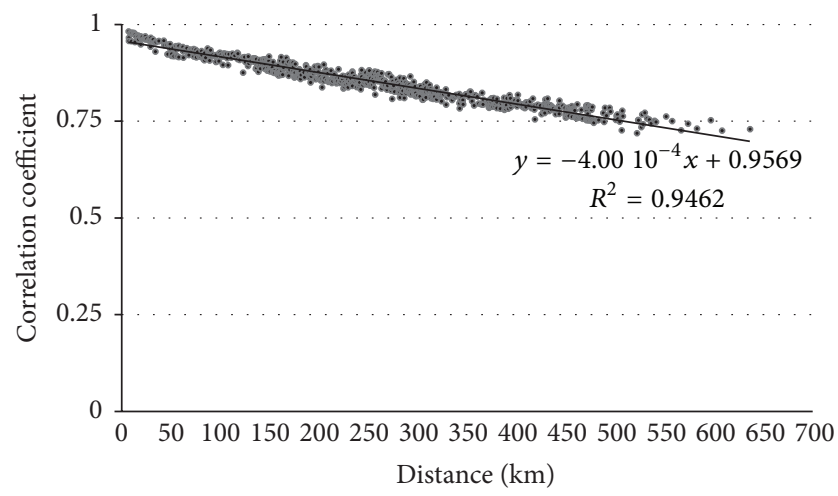

FIGURE 3: Values of correlation coefficients between irradiation time series (2010-2014 with a 15-minute time step); the uncertainty of the slope parameter is $-0.88 \%$ whereas that of the intercept parameter is $0.11 \%$.

systems are distributed must be greater than the area of the single/central PV plant. In order to thoroughly investigate this phenomena please see, for example, recent work of Elsinga and van Sark [18]. For example, the standard deviation (left dimensionless, but usually expressed as energy * area $^{-2} *$ unit of time $e^{-1}$ ) and variability index for normalized (0-1) Warsaw time series were equal to 0.249 and $0.953 \%$ whereas for a source distributed among 39 sites, they were 0.238 and $0.861 \%$. This gives a decrease by, respectively, $4.13 \%$ and $9.61 \%$. Decrease in both metrics points to the fact that the energy generation curve from such distributed sources will be smoother, meaning with smaller sudden ups and downs in available energy. This proves the existence of spatial distribution smoothing effect.

4.2. Power Load and Irradiation Patterns on a Yearly and Daily Time Frame. Power load in Poland varies and reaches it maximal values usually in December or January, whereas minimal values can be observed in May. Due to the geographical location of Poland, maximal sums of irradiation are observed in June and almost $80 \%$ of annual irradiation is observed from May to August. This leads to a conclusion that irradiation and power load are strongly anticorrelated. The value of CC which was calculated for data presented

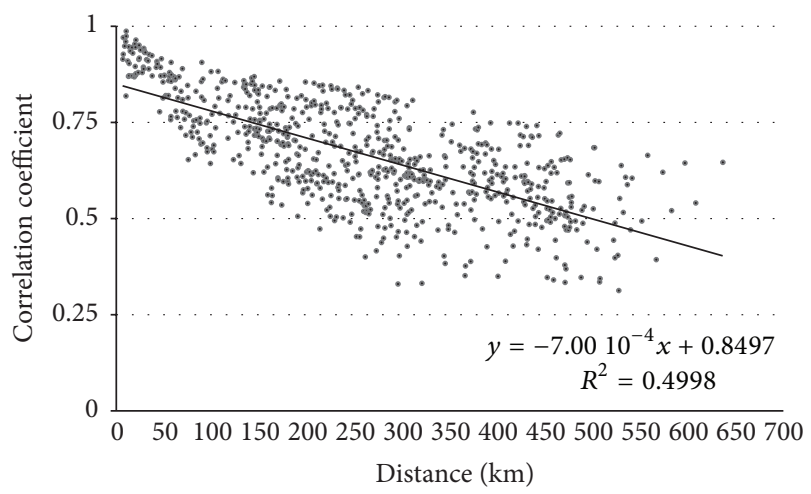

FIGURE 4: Values of correlation coefficients between irradiation time series (June 2005 with a 1-minute time step); the uncertainty of the slope parameter is $-3.68 \%$ whereas that of the intercept parameter is $0.9 \%$.

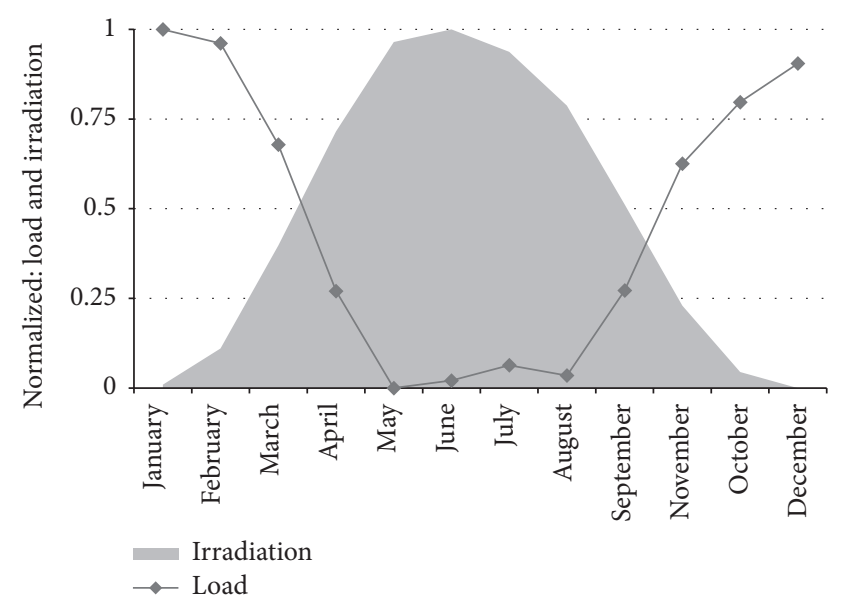

FIGURE 5: Normalized mean monthly values of irradiation and load in Poland over the years 2002-2015.

in Figure 5 is equal to -0.986 . This suggests that with an increasing share of $\mathrm{PV}$ in power system, energy surpluses will probably occur in summer.

In ideal weather conditions, irradiation is following patterns which can be calculated for each day, or even seconds over given year, based on the so-called clear-sky model [19] or [20]. However, due to the occurrence of clouds, fog, or particles in atmosphere, it is not possible to estimate the accurate amount of irradiation which will be available (in real conditions) during each day of the year. To some extent, it is possible for longer time periods: months [20].

Figure 6 presents normalized values of load and irradiation for a typical day within each month. In case of irradiation, one local peak is distinguishable within single day. Almost the same is with power load, but it is important to note that in case of this variable, only a sample from the daily pattern was investigated. A very distinct positive correlation between irradiation and power demand within the first hours of the day can be observed. This leads to the conclusion that generally photovoltaics may strongly contribute to the increasing power demand during the first 


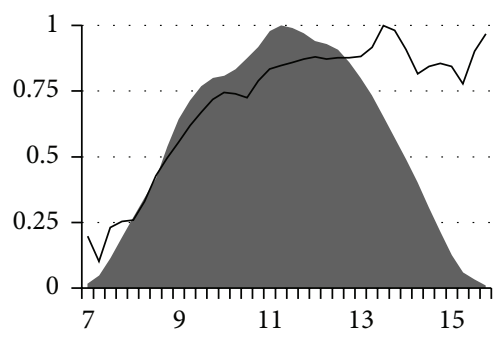

(a)

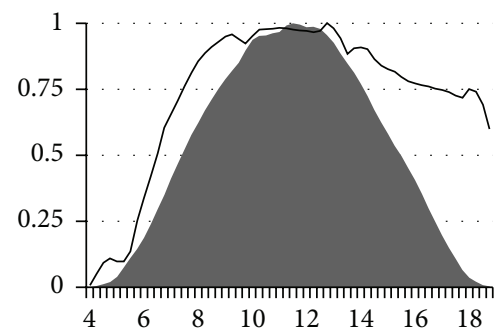

(d)

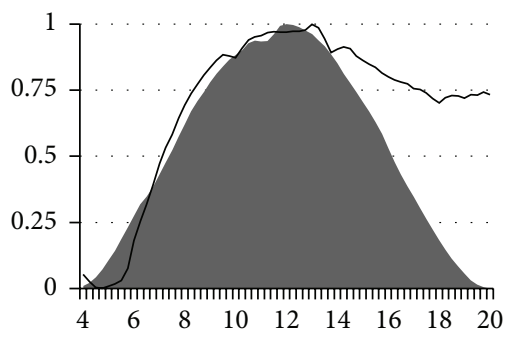

(g)

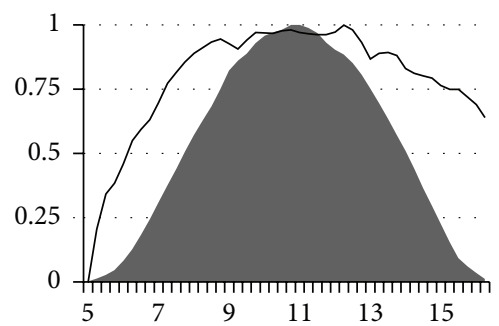

(j)

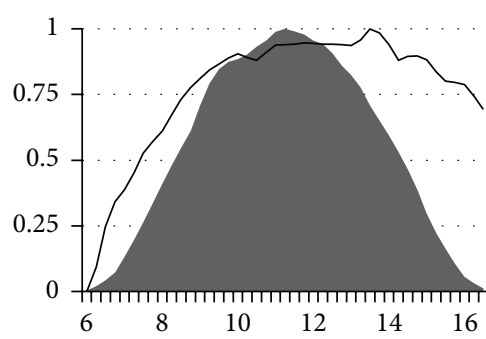

(b)

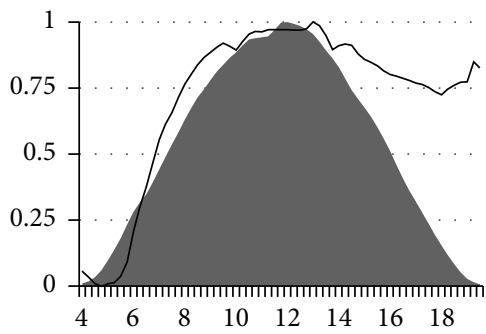

(e)

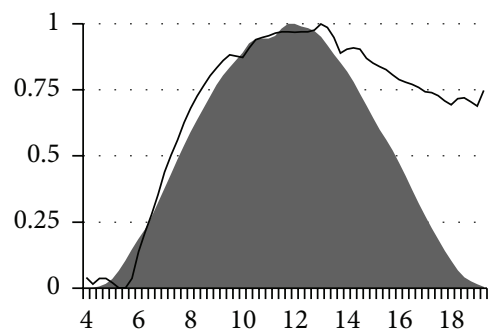

(h)

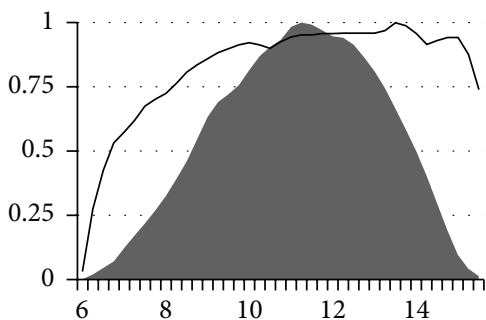

$(\mathrm{k})$

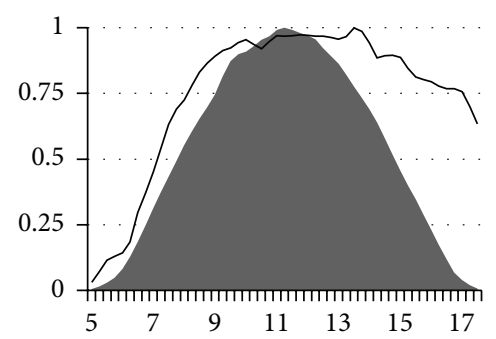

(c)

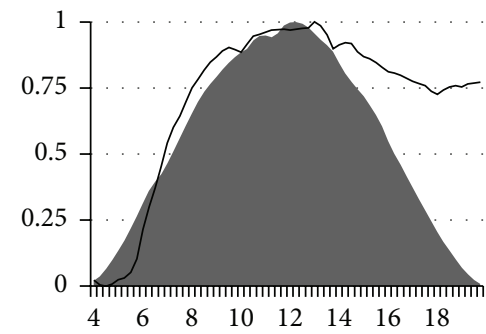

(f)

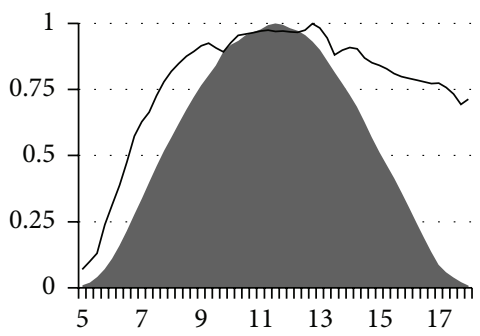

(i)

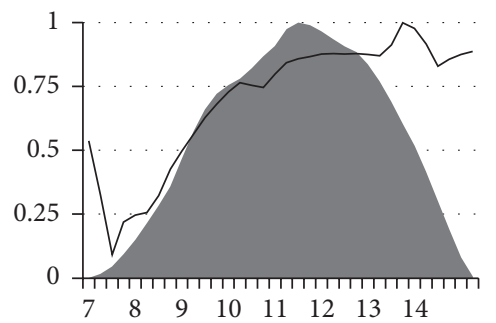

(1)

FIGURE 6: Normalized (0-1) values of irradiation and power load over the course of each month ((a), January). OX axis represents the hours of the day and $O Y$ axis represents normalized values of power load and irradiation, black line: power load, grey area irradiation.

hours of the day (from 6:00 to 13:00). However, patterns presented in Figure 6 are idealized and variable nature of irradiation imposes a need to oversize the whole energy providing system and invest in both short- and long-term energy storing infrastructure.

4.3. Integrating $P V$ to the Energy System. Based on description in Section 3.3., an analysis of PV integration to the polish energy system was conducted. Presented values of capacity installed in PV systems are theoretical and were used to determine the effect of deep market penetration by PV. One must bear in mind that on average a PV installation in polish solar conditions yields annually $950-1025 \mathrm{kWh} / \mathrm{kW}$. According to the performed calculations, whose results are presented by means of Figures 7 and 8 , one can come to the following conclusions:

(i) Increasing share of photovoltaics on covering energy demand leads to a picking-up value of variability index (Figure 7). This is identical to the fact that the energy demand is more variable over the course of the year and day; thus, it is tougher to predict energy demand which must be covered from other power units or energy storages such as pumped-storage hydroelectric power stations, which are a focus of attention in [21, 22].

(ii) Considering current annual energy demand and its patterns (which was on average equal to $157 \mathrm{TWh}$ in 
Energy demand covered from PV (\%)

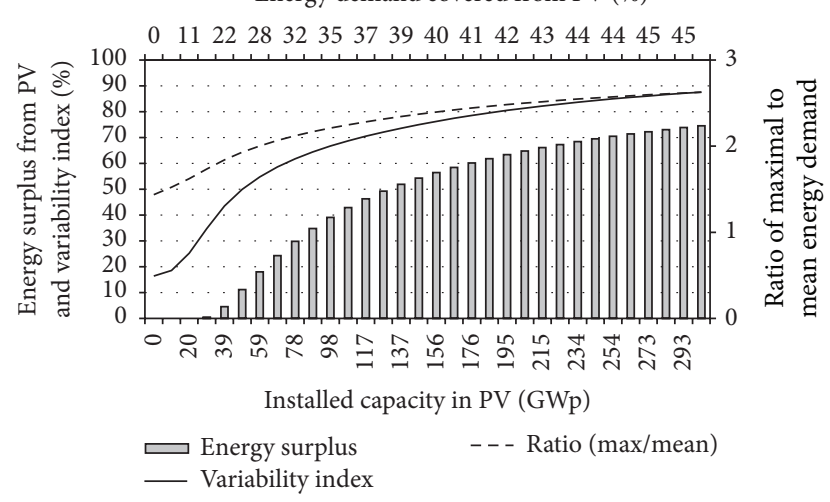

FIgURE 7: Photovoltaics impact on energy demand variability.

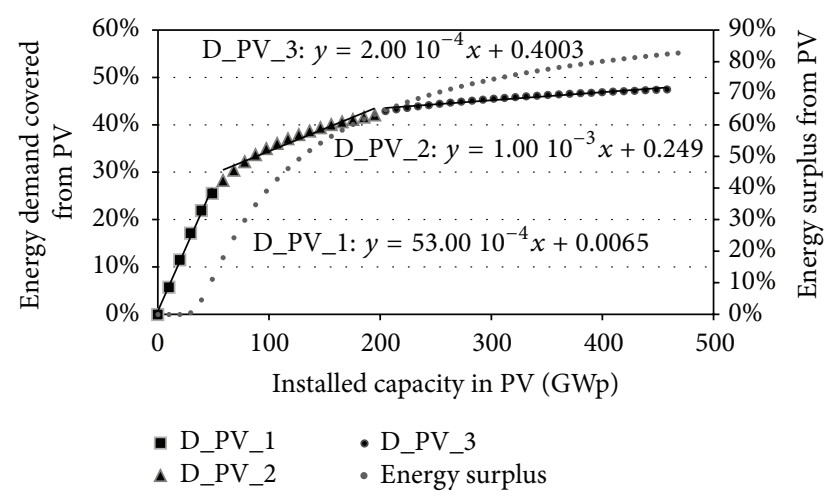

FIGURE 8: How does energy demand covered from PV and resulting energy surpluses change for different values of installed capacity in PV. Key: D_PV_1 and so forth (denoted by square, triangle, and circle) represent current demand covered from PV; in respective ranges they were approximated by linear regression equation.

period 2010-2014), the largest increase in PV share in covering current energy demand is observed when installed capacity of PV ranges from $0+$ to $50 \mathrm{GWp}$ (see Figure 8).

(iii) Further analysis of increasing installed capacity in PV systems has shown (according to the considered data) that it is not physically possible to cover more than $53 \%$ of current energy demand from PV, without energy storage devices. See on Figure 8 how slowly the energy demand is covered from PV increasing when installed capacity in PV exceeds 50 GWp.

(iv) When the share of PV covering the current energy demand exceeds $11-12 \%$ (55-60 GWp of installed capacity), greater and greater energy surpluses start to occur. For example, when installed capacity reaches $97.5 \mathrm{GWp}$ then $39 \%$ of generated energy is perceived as a surplus and must be stored or exported, not mentioning the fact that in the same time other energy sources are not generating energy at all.

(v) Energy generation from photovoltaic installations does not lead to a decrease in maximal energy demand. This is due to the fact that peak energy demand in Poland occurs after sunset. However, an increasing energy consumption resulting from greater demand for air-conditioning may be effectively covered from PV, especially BIPV (Building Integrated Photovoltaics) [23].

Overall, similarly as in the paper presented by De Jong et al. [9], a correlation between irradiation values and energy demand curve has been found. Obtained results are coherent on the fact that PV has potential to contribute to the energy generation during morning and early afternoon hours. However, presented in Figures 5 and 6, irradiation profiles are idealized, meaning they are based on averaged values of irradiation. Therefore, one should not expect such smooth curves of energy from photovoltaics on a day-today basis. According to Lorenz et al. [24], one solution is to employ regional PV energy generation forecasts to better manage energy production from conventional power units.

\section{Conclusions}

This study concludes that photovoltaics have huge potential to contribute to covering energy demand in Poland. Additionally, conducted analysis has shown that there are some boundaries which should not be crossed when it comes to the maximal capacity installed in PV plants in Poland (however, current trends show that exceeding even $1 \mathrm{GWp}$ in the immediate future is rather unlikely). This study unveiled several interesting directions for future research. First of all, there is a need to perform the thorough analysis of air conditioners impact on power demand and how it correlates with irradiation values. Secondly, a more detailed analysis of regional energy demand patterns is essential to create a model which will aim at optimally distributing variable energy sources whilst taking into the consideration limited capacities of transmissions networks. Finally, a regional potential for energy storage in form of pumped-storage or run-ofriver power plants with pondage coupled with photovoltaics should be investigated and estimated.

\section{Competing Interests}

The authors declare that they have no competing interests.

\section{References}

[1] Statistics on Electrical Power Engineering in Poland, Energy Market Agency, Warszawa, Poland, 2013.

[2] M. A. Eltawil and Z. Zhao, "Grid-connected photovoltaic power systems: technical and potential problems-a review," Renewable and Sustainable Energy Reviews, vol. 14, no. 1, pp. 112-129, 2010.

[3] Energy Regulatory Authority, http://www.ure.gov.pl/uremapoze/ mapa.html.

[4] L. E. Jones, Renewable Energy Integration: Practical Management of Variability, Uncertainty, and Flexibility in Power Grids, Academic Press, 2014.

[5] B. Burger, Stromerzeugung aus Solar- und Windenergie im Jahr 2015, Fraunhofer-Institut für solare Energiesysteme ISE, 2016. 
[6] ARE-Sytuacja w elektroenergetyce. ARE—situation in electrical power engineering. As on 2014, http://www.are.waw.pl/.

[7] J. Kleissl, Solar Energy Forecasting and Resource Assessment, Academic Press, 2013.

[8] I. H. Rowlands, B. P. Kemery, and I. Beausoleil-Morrison, "Managing solar-PV variability with geographical dispersion: an Ontario (Canada) case-study," Renewable Energy, vol. 68, pp. 171-180, 2014.

[9] P. De Jong, A. S. Sánchez, K. Esquerre, R. A. Kalid, and E. A. Torres, "Solar and wind energy production in relation to the electricity load curve and hydroelectricity in the northeast region of Brazil," Renewable and Sustainable Energy Reviews, vol. 23, pp. 526-535, 2013.

[10] J. Jurasz and J. Mikulik, "Stabilność produkcji energii elektrycznej z instalacji fotowoltaicznej-wpływ dystrybucji przestrzennej," Rynek Instalacyjny, vol. 11, pp. 35-37, 2015.

[11] http://www.soda-pro.com/.

[12] http://re.jrc.ec.europa.eu/pvgis/.

[13] http://www.pse.pl/index.php.

[14] L. W. Davis and P. J. Gertler, "Contribution of air conditioning adoption to future energy use under global warming," Proceedings of the National Academy of Sciences of the United States of America, vol. 112, no. 19, pp. 5962-5967, 2015.

[15] S. Jerez, R. M. Trigo, A. Sarsa, R. Lorente-Plazas, D. PozoVázquez, and J. P. Montávez, "Spatio-temporal complementarity between solar and wind power in the Iberian Peninsula," Energy Procedia, vol. 40, pp. 48-57, 2013.

[16] A. Z. Sahin and S. Rehman, "Economical feasibility of utilizing photovoltaics for water pumping in Saudi Arabia," International Journal of Photoenergy, vol. 2012, Article ID 542416, 9 pages, 2012.

[17] A. Beluco, P. K. de Souza, and A. Krenzinger, "A dimensionless index evaluating the time complementarity between solar and hydraulic energies," Renewable Energy, vol. 33, no. 10, pp. 2157$2165,2008$.

[18] B. Elsinga and W. van Sark, "Spatial power fluctuation correlations in urban rooftop photovoltaic systems," Progress in Photovoltaics: Research and Applications, vol. 23, no. 10, pp. 1390-1397, 2015.

[19] R. E. Bird and R. L. Hulstrom, "Simplified clear sky model for direct and diffuse insolation on horizontal surfaces," Tech. Rep. SERI/TR-642-761, Solar Energy Research Institute, Golden, Colo, USA, 1981.

[20] A. A. Sabziparvar, "General formula for estimation of monthly mean global solar radiation in different climates on the south and north coasts of Iran," International Journal of Photoenergy, vol. 2007, Article ID 94786, 7 pages, 2007.

[21] P. Punys, R. Baublys, E. Kasiulis, A. Vaisvila, B. Pelikan, and J. Steller, "Assessment of renewable electricity generation by pumped storage power plants in EU Member States," Renewable and Sustainable Energy Reviews, vol. 26, pp. 190-200, 2013.

[22] Interview: what is driving the hydropower renaissance?, https:// www.hydropower.org.

[23] B. A. Jubran, H. A. Al-Hinai, Y. H. Zurigat, and S. Al-Salti, "Feasibility of using various photovoltaic systems for windowtype air-conditioning units under hot-arid climates," Renewable Energy, vol. 28, no. 10, pp. 1545-1553, 2003.

[24] E. Lorenz, T. Scheidsteger, J. Hurka, D. Heinemann, and C. Kurz, "Regional PV power prediction for improved grid integration," Progress in Photovoltaics: Research and Applications, vol. 19, no. 7, pp. 757-771, 2011. 

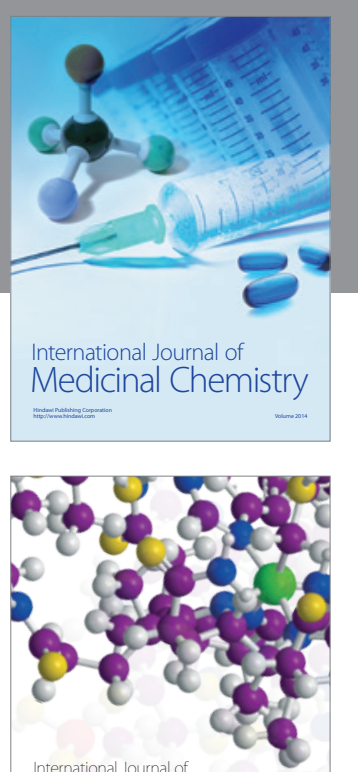

Carbohydrate Chemistry

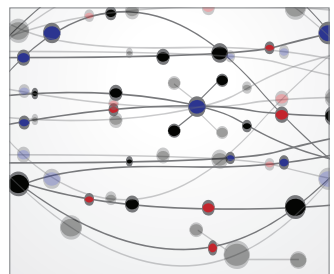

The Scientific World Journal
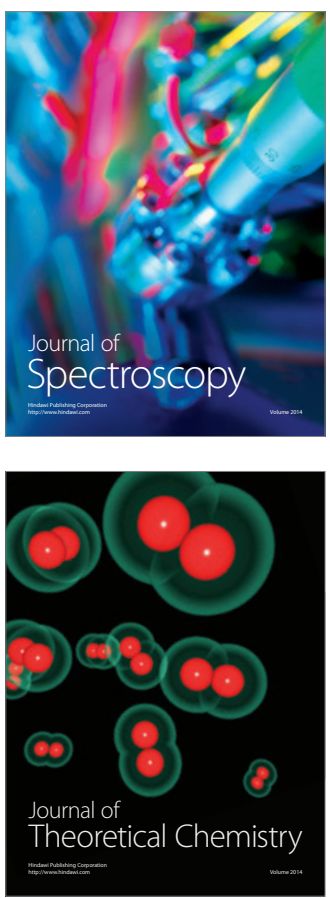
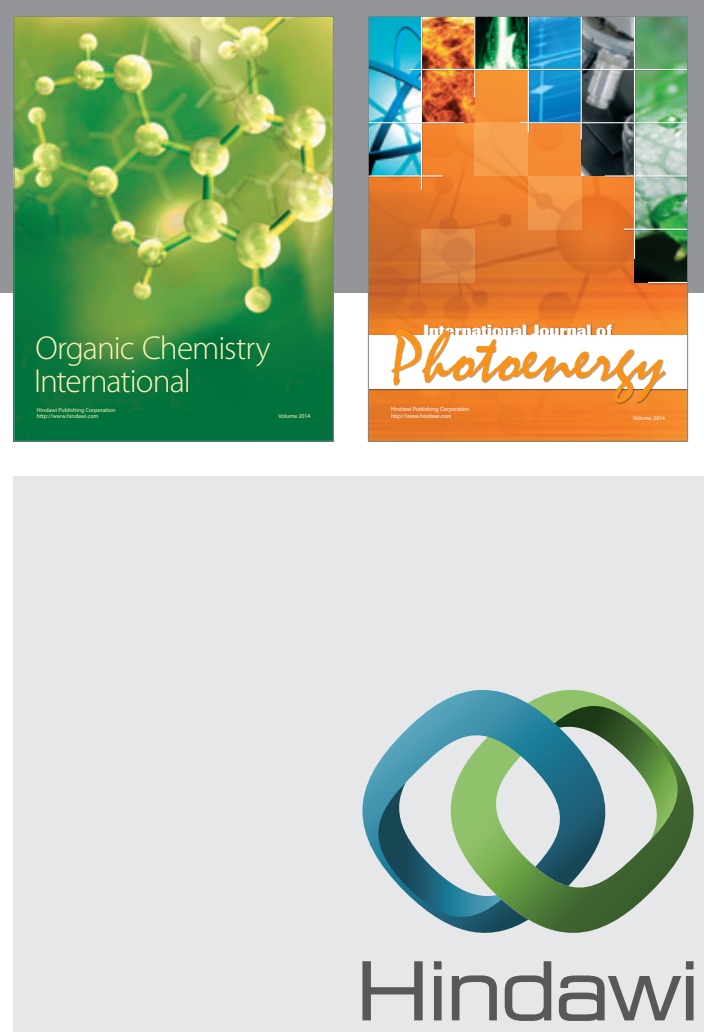

Submit your manuscripts at

http://www.hindawi.com

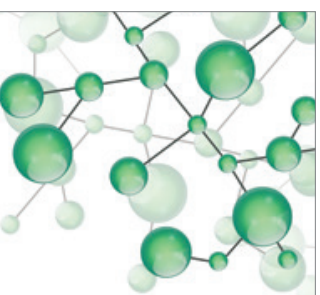

International Journal of

Inorganic Chemistry

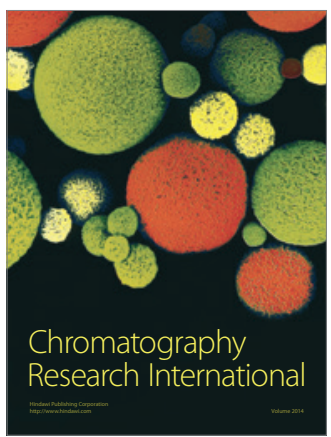

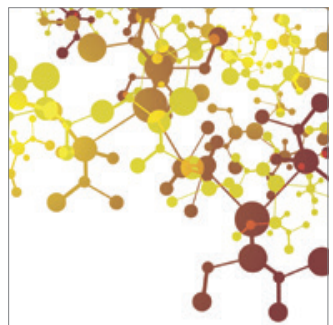

Applied Chemistry
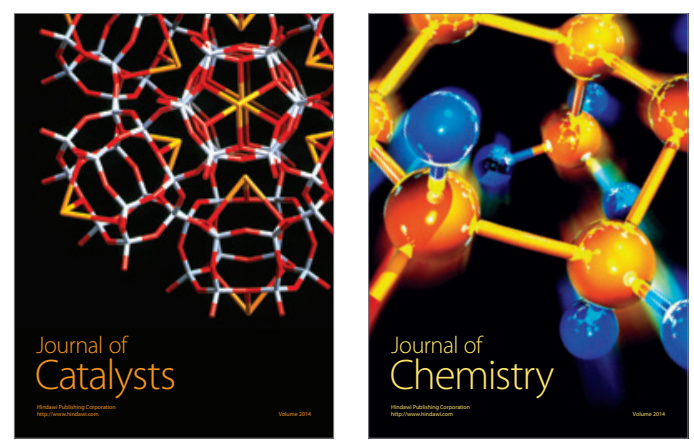
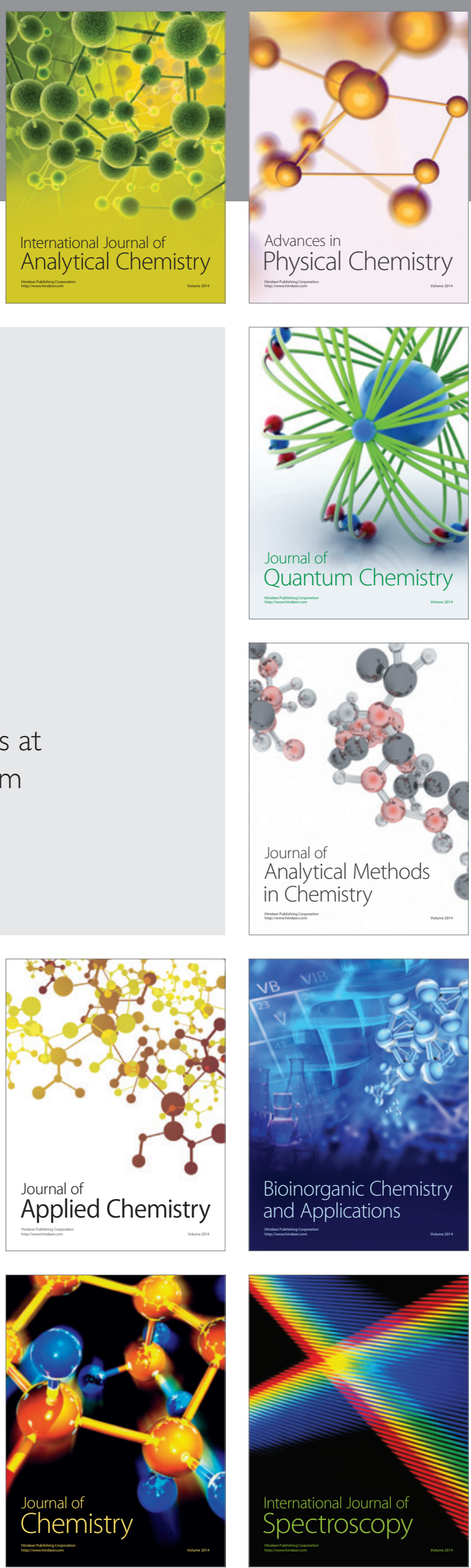